Psychother Psychosom 2014;83:382-383

DOI: $10.1159 / 000365151$

\section{Instability of Depression Severity at Intake as a Moderator of Outcome in the Treatment for Major Depressive Disorder}

\section{Sigal Zilcha-Mano ${ }^{a}$, Jacques P. Barber ${ }^{b}$}

a Department of Psychology, University of Haifa, Haifa, Israel; ${ }^{b}$ Gordon F. Derner Institute of Advanced Psychological Studies, Adelphi University, Garden City, N.Y., USA

Initial treatment for depression may not result in remission in up to two thirds of patients [1]; therefore, pretreatment predictors of outcomes are important in determining the optimal treatment for each patient. Previous studies have explored patients' baseline characteristics as moderators that may identify for whom and under what circumstances distinct treatments have the most optimal effects. However, these studies have been largely unsuccessful in predicting treatment outcome [2]. The present study examined whether changes in the severity of depression during intake may predict treatment outcome.

The study setting and participants have been previously described [3]. Patients diagnosed with MDD $(n=156)$ were randomized to one of three treatment conditions: supportive-expressive therapy (SET; $\mathrm{n}=51)$, antidepressant medication $(\mathrm{MED} ; \mathrm{n}=55)$ or pill placebo $(\mathrm{PBO} ; \mathrm{n}=50)$. Patients were excluded from randomization for not meeting MDD criteria $(\mathrm{n}=74)$, a Hamilton Rating Scale for Depression (HRSD) score $<14$ on first $(\mathrm{n}=4)$ or second evaluation (performed a week later; $\mathrm{n}=1$ ), the presence of primary disorders other than depression $(n=45)$ and high suicide risk $(n=9$; patients could meet multiple criteria). Depressive symptoms were assessed with the HRSD [4]. The difference between the first and second pretreatment evaluations served as an operationalization of pretreatment changes in depressive symptoms. Treatments were provided for a total of 16 weeks. HRSD assessments throughout active treatment were conducted at weeks $2,4,6,8,12,15$ and 16 and served as continuous measures of outcomes.

Multilevel modeling was performed using PROC MIXED in SAS. A logarithmic transformation (loge[week+1]) was used to quantify change. We conducted two longitudinal models to examine the effect of changes in pretreatment HRSD scores (PT-HRSD) on outcomes. The first model tested the effect of PT-HRSD on changes in outcome over time for the entire cohort, while the second examined differences between treatment conditions. In both models, we controlled for pretreatment levels of depression severity.

The mean age of the study cohort was 37.5 years $(\mathrm{SD}=12.2)$; 92 patients were female. No baseline differences in demographic and clinical characteristics were found between the treatment conditions. The mean pretreatment HRSD score was $20.3 \pm 4.06 ; 17$ patients showed identical HRSD scores in the two evaluations, while the scores decreased in 87 patients and increased in 52 (mean change: $-0.9 \pm 3.5$ ). When evaluating whether PT-HRSD instability predicted symptomatic change throughout treatment, we found that the omnibus test for the two-level interaction between time and PT-HRSD in predicting changes in outcomes was significant $[\mathrm{B}=-0.11, \mathrm{SE}=0.04, \mathrm{t}(788)=-2.65, \mathrm{p}=0.008]$. Specifically, the estimated slope of the outcomes throughout the course of treatment was -2.69 if PT-HRSD $=0$ (i.e., stable pretreatment depressive symptoms). A decrease in pretreatment depressive symptoms (PT-HRSD) by $1 \mathrm{SD}$ (which is equal to $3.5 \mathrm{HRSD}$ points) predicts a less rapid reduction in symptoms throughout treatment (an increase of $\mathrm{B}=0.41$ in the negative slope of change).

We next evaluated whether the ability of PT-HRSD to predict outcomes differs among the treatments. The omnibus test for the three-level interaction between time, PT-HRSD and type of treatment in predicting outcomes was significant $[\mathrm{F}(2,785)=4.30, \mathrm{p}=$ 0.013]. Specifically, the effect of PT-HRSD on the slope of changes in outcomes over time for MED and SET was found to be significantly different from $\mathrm{PBO}[\mathrm{B}=0.23, \mathrm{SE}=0.10, \mathrm{t}(785)=2.18, \mathrm{p}=$ 0.02 for MED; $\mathrm{B}=0.33, \mathrm{SE}=0.11, \mathrm{t}(785)=2.81, \mathrm{p}=0.005$ for $\mathrm{SET}]$. Specifically, patients whose HRSD scores decreased by $\geq 1.15$ points responded better to SET than PBO. Similarly, patients whose scores decreased by $\geq 0.7$ points responded better to MED than PBO. As can be seen in table 1, the largest effect of PT-HRSD on the slope of changes in outcomes over time was in the placebo condition.

Previous reports regarding predictors of treatment outcome for MDD found that early improvement throughout treatment was a predictor of stable response [5]. However, to the best of our knowledge, changes in severity of depression during the initial assessment of depressed patients have not been evaluated as predictors of treatment outcome. In the current study, involving patients meeting the MDD diagnosis and having HRSD scores of $\geq 14$ at 2 separate measurement points 1 week apart, pretreatment changes in depressive symptoms significantly predicted symptomatic change throughout the course of treatment even after controlling for pretreatment severity of depression. Importantly, although the original analyses of these data demonstrated no overall differences in treatment outcome between the treatment groups [3], significant differences in the response to the two active treatments (psychotherapy and medication) versus control were apparent if using pretreatment depression stability as a moderator. If validated in future studies, pretreatment changes in depressive symptoms may be used to predict treatment outcomes and aid in treatment selection.

Interestingly, the largest effect of pretreatment depressive severity stability on outcomes was in the placebo condition. This suggests that instability of depression at intake is a highly sensitive predictor of the placebo versus medication and psychotherapy responses, and may help determine the magnitude of the placebo effect throughout treatment. Further studies are required in order to validate these findings and examine the underlying mechanism of this association.

\section{KARGER}

E-Mail karger@karger.com

www.karger.com/pps (c) 2014 S. Karger AG Basel

$0033-3190 / 14 / 0836-0382 \$ 39.50 / 0$
Sigal Zilcha-Mano, $\mathrm{PhD}$

Department of Psychology, University of Haifa Haifa 31905 (Israel)

E-Mail sigalzil@gmail.com 
Table 1. Treatment response in patients who showed a decrease or increase in pretreatment depression stability (PT-HRSD) and slope estimates for the within-condition effect of PT-HRSD on changes in depressive symptoms throughout treatment

\begin{tabular}{|c|c|c|c|c|c|c|c|c|c|}
\hline & \multicolumn{2}{|l|}{ Responders, \% } & \multicolumn{2}{|l|}{ Remitters, \% } & \multicolumn{4}{|c|}{ Slope estimation for the within-condition effect } & \multirow[t]{2}{*}{$\mathrm{p}$} \\
\hline & PT-HRSD $<0$ & PT-HRSD $\geq 0$ & PT-HRSD $<0$ & PT-HRSD $\geq 0$ & values of PT-HRSD & $\begin{array}{l}\text { slope } \\
\text { estimate }\end{array}$ & SE & $\mathrm{z}$ value & \\
\hline $\begin{array}{l}\text { MED } \\
(n=55)\end{array}$ & 34.48 & 26.92 & 31.03 & 19.23 & $\begin{array}{l}\text { mean PT-HRSD } \\
\text { mean PT-HRSD }+1 \text { SD } \\
\text { mean PT-HRSD }-1 \text { SD }\end{array}$ & $\begin{array}{l}-2.748 \\
-2.995 \\
-2.502\end{array}$ & $\begin{array}{l}0.266 \\
0.390 \\
0.307\end{array}$ & $\begin{array}{r}-10.30 \\
-7.67 \\
-8.13\end{array}$ & $\begin{array}{l}<0.0001 \\
<0.0001 \\
<0.0001\end{array}$ \\
\hline $\begin{array}{l}\text { SET } \\
(n=51)\end{array}$ & 31.25 & 21.05 & 28.12 & 10.52 & $\begin{array}{l}\text { mean PT-HRSD } \\
\text { mean PT-HRSD +1 SD } \\
\text { mean PT-HRSD -1 SD }\end{array}$ & $\begin{array}{l}-2.446 \\
-2.345 \\
-2.548\end{array}$ & $\begin{array}{l}0.319 \\
0.548 \\
0.276\end{array}$ & $\begin{array}{l}-7.65 \\
-4.28 \\
-9.23\end{array}$ & $\begin{array}{l}<0.0001 \\
<0.0001 \\
<0.0001\end{array}$ \\
\hline $\begin{array}{l}\mathrm{PBO} \\
(\mathrm{n}=50)\end{array}$ & 19.23 & 29.16 & 11.53 & 29.16 & $\begin{array}{l}\text { mean PT-HRSD } \\
\text { mean PT-HRSD }+1 \text { SD } \\
\text { mean PT-HRSD }-1 \text { SD }\end{array}$ & $\begin{array}{l}-3.095 \\
-4.120 \\
-2.071\end{array}$ & $\begin{array}{l}0.297 \\
0.486 \\
0.298\end{array}$ & $\begin{array}{r}-10.42 \\
-8.47 \\
-6.93\end{array}$ & $\begin{array}{l}<0.0001 \\
<0.0001 \\
<0.0001\end{array}$ \\
\hline
\end{tabular}

Responders: percentage of patients who were considered responders at the end of treatment (i.e., HRSD score $\leq 9$ or $50 \%$ HRSD score reduction and HRSD score $\leq 12$ ). Remitters: percentage of patients who were considered remitters at the end of treatment (i.e., no longer meeting criteria for MDD and HRSD score $<8$ ).

\section{Disclosure Statement}

S. Zilcha-Mano has received funding from the Fulbright Program. J.P. Barber has received funding from the National Institute of Mental Health (NIMH) and the National Institute on Drug Abuse (NIDA), authors' fees from Guilford Press, Basic Books and Cambridge University Press and honoraria from Lundbeck.

\section{References}

1 Rush AJ, Trivedi MH, Wisniewski SR, Nierenberg AA, Stewart JW, Warden D, Niederehe G, Thase ME, Lavori PW, Lebowitz BD, McGrath PJ, Rosenbaum JF, Sackeim HA, Kupfer DJ, Luther J, Fava M: Acute and longer-term outcomes in depressed outpatients requiring one or several treatment steps: a STAR*D report. Am J Psychiatry 2006;163:1905-1917.
-2 Frank E, Cassano GB, Rucci P, Thompson WK, Kraemer HC, Fagiolini A, Maggi L, Kupfer DJ, Shear MK, Houck PR, Calugi S, Grochocinski VJ, Scocco P, Buttenfield J, Forgione RN: Predictors and moderators of time to remission of major depression with interpersonal psychotherapy and SSRI pharmacotherapy. Psychol Med 2011;41:151-162.

3 Barber JP, Barrett MS, Gallop R, Rynn MA, Rickels K: Short-term dynamic psychotherapy versus pharmacotherapy for major depressive disorder: a randomized, placebo-controlled trial. J Clin Psychiatry 2012;73: 66-73.

4 Hamilton M: Development of a rating scale for primary depressive illness. Br J Soc Clin Psychol 1967;6:278-296.

5 Tadic A, Helmreich I, Mergl R, Hautzinger M, Kohnen R, Henkel V, Hegerl $\mathrm{U}$ : Early improvement is a predictor of treatment outcome in patients with mild major, minor or subsyndromal depression. J Affect Disord 2010;120:86-93. 